\title{
NOTAS PRELIMINARES SOBRE POLÍTICAS PÚBLICAS E ESPAÇOS TURÍSTICOS EM OIAPOQUE/AP-BRASIL
}

PRELIMINARY NOTES ON PUBLIC POLICIES AND TOURIST SPACES IN OIAPOQUE/AP-BRAZIL

Rubio José FERREIRA ${ }^{1}$

Célia dos Santos NARCISO ${ }^{2}$

Artigo recebido em 13/03/2018 e aceito em 30/07/2018

Palavras-chave:
Turismo;
Oiapoque;
Políticas Públicas.

Keywords:

Tourism;

Oiapoque;

Public Policy.

\section{R E S U M O}

Com o objetivo de contribuir para o debate em torno do planejamento e da gestão do turismo em Oiapoque, no estado no Amapá, a pesquisa desenvolvida no âmbito do Programa Institucional de Bolsas de Iniciação Científica (PIBIC) partiu do pressuposto de que é preciso conhecer o real para planejar o ideal desejado e, assim, avançar no sentido de mudanças positivas que alcancem todos os grupos sociais. Com caráter explicativo, a pesquisa que foi baseada nos conceitos e categorias de análise espacial, dinâmicas espaciais e políticas públicas dá conta que no tocante ao turismo, que tem como base o deslocamento de pessoas, preponderantemente para fins de lazer e descanso, demanda um conjunto de infraestruturas, para o que as políticas públicas exercem papel relevante. Embora haja alguma articulação das ações dos governos no sentido de alavancar o turismo em Oiapoque, precisa-se criar mecanismos que tornem o turismo naquele lugar um dos instrumentos para o desenvolvimento local. Do contrário, os espaços turísticos de Oiapoque continuarão sendo excludentes.

\section{A B S T R A C T}

With the objective of contributing to the debate around the planning and management of tourism in Oiapoque, in the state of Amapá, the research developed started from the hypothesis that it is necessary to know the real to plan the desired ideal and thus to move towards positive changes that reach all social groups. With explanatory character, the research that was based on the concepts and categories of spatial analysis, spatial dynamics and public policie identified that tourism, which is based on the displacement of people for recreation, demands a set of infrastructures for which public policies play a relevant role Although there are some articulation actions of governments to develop tourism in Oiapoque, it is necessary to create mechanisms that make tourism in that place one of the instruments for local development. Otherwise, the tourist areas of Oiapoque will continue to be exclusive.

\section{NOTAS INTRODUTÓRIAS}

O presente texto resulta de pesquisa realizada no âmbito do Programa Institucional de Bolsas de Iniciação Científica (PIBIC) com apoio da Fundação de Amparo à Pesquisa do Amapá (FAPEAP) e do Conselho Nacional de Desenvolvimento Científico e Tecnológico (CNPq). O espaço é produzido

\footnotetext{
1 Universidade Federal do Oeste da Bahia (UFOB). E-mail: rubio.ferreira@ufob.edu.br.

2 Universidade Federal do Amapá (UNIFAP). E-mail: celiasantostrindade@outlook.com.
} 
socialmente, logo, as ações de cada agente interferem na sua organização. Por sua vez, o turismo, como uma atividade social e econômica, pode contribuir para a própria realização do espaço. Diante disso, e pensando nos espaços turísticos de Oiapoque, surgem questões do tipo: porque as políticas públicas de turismo em Oiapoque, até o presente, não foram capazes de alavancar o turismo local? Quais tem sido as ações do Governo Municipal no sentido de desenvolver o turismo nesse município? Quem seriam os principais beneficiários das políticas públicas para o turismo naquele lugar?

Partindo do pressuposto que políticas púbicas que visem contribuir para o desenvolvimento dessa atividade, apenas cumprem seu papel se, na sua gestão, a população local estiver inserida efetivamente em todo o processo de planejamento, desde a elaboração das políticas públicas até a sua implementação, o texto busca elucidar algumas dessas questões, com o sentido maior de contribuir para o debate em torno do planejamento e da gestão do turismo em Oiapoque.

A pesquisa de caráter explicativo baseou-se nos conceitos e categorias de análise, a saber: análise espacial, dinâmicas espaciais e políticas públicas. Os procedimentos metodológicos proporcionaram a realização de descrições dos processos de produção dos espaços turísticos. Esses procedimentos, Flick (2009) chama de "método da triangulação", pois articula diversos procedimentos qualitativos e quantitativos, dando-lhes igual relevância.

0 turismo, como uma atividade social, tradicionalmente classificada no setor terciário, vem tendo destaque para as economias em quase todo o mundo, contribuindo para o crescimento econômico de diversas regiões. Ao mesmo tempo, uma análise geográfica do turismo não deve deixar de levar em conta o seu papel na reprodução social, uma vez que se constitui de uma prática socioespacial.

Para além da denominação tradicional das atividades econômicas por setores, também o turismo deve ser analisado como parte do processo econômico. Em outras palavras, as formas espaciais refletem a dinâmica do sistema econômico em atividades de produção, distribuição e consumo; em que cada atividade corresponde a uma espacialidade e a uma temporalidade que se manifesta concretamente no espaço (RIO, 2012).

A base do turismo é o deslocamento de pessoas, preponderantemente para fins de lazer, o que demanda, dente outros, um conjunto de infraestruturas. Nesse sentido, as políticas públicas exercem papel relevante. Para que o desenvolvimento dos espaços turísticos se efetive é preciso que se considerem todos os atores/agentes sociais envolvidos, uma vez que, cada um, à sua medida, contribui para a produção e reprodução do espaço. É nesse aspecto que a análise espacial do turismo se faz necessária, especialmente quando se pretende analisar o papel dos agentes sociais do espaço geográfico no que tange à realização do turismo.

Dentre os atores/agentes sociais envolvidos com a atividade turística, destaca-se o Estado que tem, dentre outras, a função de desenvolver políticas públicas que visem à melhoria da qualidade de 
vida de forma equitativa, para toda a sociedade. Outros agentes sociais são: a própria sociedade, como também, as forças econômicas, as quais, como mostra Santos (2011), procuram mecanismos de expansão do capital no espaço, através das formas espaciais, transformando-o em superfície comercial, seletivamente quando apresenta as melhores condições para o mercado. Neste contexto, vale salientar que o turismo é apenas uma atividade no espaço; portanto, não deve ser visto como a responsável pelo desenvolvimento socioespacial tão desejado.

As políticas públicas para o turismo exercem papel relevante para o seu desenvolvimento ou contração, e até eliminação. Portanto, o planejamento e a gestão do turismo, nas mais diferenciadas escalas, devem ser realizados considerando todos os fatores para sua realização de maneira articulada e sistêmica.

Ao buscar compreender o próprio conceito de turismo e apreender a articulação das políticas públicas com a sua realização, é preciso analisar como os agentes sociais, sejam públicos ou privados, ou sociedade civil, vinculados ao turismo, executam suas ações e contribuem para a realização dos espaços turísticos e então, é possível entender e refletir a que serve o turismo em Oiapoque, um município localizado no interior da Amazônia Brasileira.

\section{POLÍTICAS PÚBLICAS E TURISMO}

O fenômeno turístico, que tem sido estudado por diversos pensadores, ainda é considerado um ramo do conhecimento relativamente recente, já que os primeiros estudos datam de 1911 (BARRETO, 1995). Se no início do século XX, o turismo parecia uma atividade fabulosa e salvadora, mais recentemente Yázigi (1999) desmitifica essa ideia, ainda que tal atividade seja importante impulsionadora da economia contemporânea. Se por um lado, trata-se de uma atividade muito dinâmica e complexa por demandar um conjunto de serviços, equipamentos, infraestrutura, etc. (BARRETTO, 1995), ao dinamizar a economia e, dinamiza também, a forma, a função e a estrutura do espaço turístico.

Compreendendo o turismo como um conjunto complexo de bens e serviços que tem por objetivo facilitar e oferecer produtos, equipamentos e entretenimento, pode-se entender que a atividade turística engloba uma diversidade de fatores, sejam eles de valor paisagístico, histórico e ambiental, que envolve também todos os setores e classes sociais, portanto, abrangem as relações entre a população local, turistas, rede privada e políticas públicas (ANDRADE, 1998). Daí a importância do Estado, mas não apenas ele nesse processo, uma vez que é não é o único responsável pela formulação e operacionalização de políticas públicas voltadas ao desenvolvimento do turismo (RUBINO, 2004). 
Sobre esse aspecto, Selva (2012) diz que para que os objetivos econômicos e sociais da atividade turística sejam alcançados, é necessário fazer um planejamento nas áreas receptoras de maneira integrada aos demais setores que respondem pela dinâmica do local e as relações com o ambiente interno e externo; incluindo-se nesse bojo a estrutura de gestão nas escalas de governos municipal e estadual e federal, além da iniciativa privada. Esses objetivos econômicos e sociais do turismo deverão ser viabilizados através de uma estrutura municipal de gestão colegiada, descentralizada do turismo. Para essa autora, o turismo é uma prática social fortemente territorializada e igualmente territorializante, capaz de introduzir nos lugares sua lógica de organização espacial.

Porém, vale ressaltar que a prática do turismo mostra que deve ser tratada por mais de um organismo da gestão pública e não apenas por uma secretaria de turismo, pois as interfaces entre turismo e outras práticas sociais e produtivas são múltiplas, fortes e evidentes. 0 turismo é capaz de trazer grandes benefícios para municípios, regiões e países. Mas para que haja desenvolvimento é preciso que o município desenvolva mecanismos para o planejamento e a gestão articulados e integrados, qualificando mão de obra local.

O turismo ocupa um papel importante na economia mundial, podendo ser considerado como uma das atividades mais eficazes da economia contemporânea, fazendo assim, parte do cotidiano da sociedade de consumo. Sobre esse aspecto, Coriolano (1998) diz que o turismo é um dos principais serviços de apoio a produção e boa forma de consumo para a sociedade moderna. Dessa maneira, deve-se analisar a estrutura do sistema de turismo, o planejamento e a gestão, a infraestrutura, a oferta e a demanda, englobando as relações com o meio. Isso quer dizer que, se uma análise ou gestão do turismo não considerar todos estes aspectos provavelmente apresentará muitas falhas.

Ainda no sentido de entender o turismo, faz-se necessário atentar para a importância da paisagem para essa atividade social. Yázigi (2001) afirma que a paisagem é, per se, um elemento de grande importância. Isso porque, é constituída de conjuntos de elementos naturais e humanizados que se observa em um lugar. Portanto, não se pode negligenciar nem os seus elementos naturais, tais como: forma de relevo, vegetação etc. nem os elementos humanizados da paisagem. Isso, também porque, a paisagem, como parte visual do espaço, é um dos elementos mais importantes de atração turística, e, portanto, da realização do turismo, o qual, por sua vez, deve ser visto como um todo. Ou seja, numa perspectiva de sistema.

Na perspectiva sistêmica do turismo, Beni (1998) defende que para que ele seja sustentável, devemos levar em conta todos os aspectos e processos da sua realização. Não só a "conservação" dos recursos naturais. É necessário destacar a importância dos agentes sociais locais, como a paisagem, a cultura, a população e o meio ambiente como o todo. 
Se o turismo é uma prática social, não se pode desconsiderar a sua espacialidade. Isto porque, "as práticas sociais interagem com o espaço, apropriando-se dele, transformando-o" (CASTRO; GOMES; CORRÊA, 2013). Nesse contexto, Castilho $(2006,2012)$ defende que o turismo constitui uma atividade não somente econômica, mas uma prática socioespacial, logo constitui-se de fator importante no processo de produção do espaço geográfico.

Nesse contexto, vale destacar a importância da análise espacial para entender o turismo, considerando o crescimento das atividades mais valorizadas no ponto de vista econômico em cada momento da dinâmica capitalista.

Para que o lugar seja forte, a sociedade deverá ter condições de participar ativamente com liberdade e conhecimento da causa, do processo de construção do seu lugar de vida e trabalho. É dessa forma que se poderá contribuir para uma reflexão sobre as reais possibilidades de integrar socioespacialmente as pessoas. Isso, não somente nos mercados de trabalho e consumo, mas também, e, sobretudo, na sociedade.

Se assim o for, o turismo é percebido, também, pelos grupos sociais mais pobres dos inúmeros lugares em que chega, como mecanismo mediante o qual as pessoas poderão conseguir emprego ou ocupação e, por seu turno, renda. Tudo isso, com vista à sua mobilidade socioespacial (CASTILHO, 2012). Por outro lado, vale destacar que o turismo, de fato, não garante empregabilidade de boa parte da população tal qual se almeja. Pelo contrário, essa forma de turismo não tem sido capaz de oferecer participação autônoma das comunidades. Os agentes hegemônicos é quem ditam as regras. Para que se vislumbre um turismo que seja capaz de garantir autonomia para as comunidades, é preciso que a comunidade seja efetivamente incluída no processo. 0 que se vê é que o processo inclusão comunitária não se realiza de imediato, mas permanece como uma expectativa para o futuro.

Daí, novamente, a importância das políticas públicas para o turismo. Barretto (2005) diz que o papel das políticas públicas de turismo deveria ser o de propiciar o desenvolvimento harmônico do turismo, cabendo ao Estado construir infraestrutura para essa atividade, ao mesmo tempo em que busque beneficiar e atender a população local. Assim sendo, cabe ao Estado o papel do planejamento e controle de investimentos, permitindo, também, a iniciativa privada para o desenvolvimento.

Segundo Seshi (2010), as políticas públicas (public policies), devem ser entendidas, em linhas gerais, como orientações para decisões e ações no sentido de resolverem problemas públicos. Portanto, pensar em políticas públicas, dentre elas as de turismo, remete a necessidade de se considerar a dimensão social do desenvolvimento (HÖFLING 2001). Até porque, como já dito, com o planejamento, o turismo poderá ser capaz de provocar mudanças estruturais, institucionais ou comportamentais desejadas por um grupo social ou por alguma instituição, de forma que o resultado final represente uma oportunidade de melhoria para a coletividade local e regional. 
0 planejamento do turismo se mostra poderoso instrumento de desenvolvimento socioeconômico de uma comunidade, se sua base for a própria comunidade, num tipo de turismo chamado de comunitário. Para tanto, faz-se necessário que o planejamento garanta os direitos e deveres da sociedade, na ampliação dos benefícios dessa atividade, os quais ultrapassem os anseios do capital. Ou seja, que supere a lógica capitalista que tanto gera desequilíbrios em vários âmbitos, como o da economia, social e cultural. Do contrário, apenas alguns grupos se beneficiam do turismo.

Barreto (2005), diz que o planejamento turístico envolve sistema, processo e mecanismo, com ações voltadas para o futuro. Sendo assim, este planejamento deve considerar 4 aspectos, quais sejam: i) um sistema de ideias organizado racionalmente para determinar mentalmente o que fazer para intervir em determinado contexto depois de consultar as circunstâncias concorrentes; ii) um processo de determinação de objetos e dos meios que possibilitem sua consecução; iii) um conjunto de modelos normativos e de teorias operacionais; e iv) um mecanismo orientado para um futuro desejado com os meios efetivos para tornar esse futuro uma realidade.

O planejamento turístico, portanto, integra-se a outros processos de planejamento mais amplos, visando promover melhorias econômica, social e ambiental para o local, região ou país envolvido, por meio do desenvolvimento adequado da atividade turística (PHILIPPI JR; PELICIONI, 2009). Destarte, requer profissionais capacitados e especializados que considerem, também, os elementos estruturais para o turismo no sentido de estabelecer uma efetivação entre turista e lugar visitado, levando assim o desenvolvimento turístico municipal.

Vale salientar que o planejamento do turismo não pode ser visto de forma isolada, até mesmo porque gera investimento cujo gerenciamento pode ser de ordem pública ou privada (BARRETO, 2005), para então se vislumbrar o desejado desenvolvimento turístico.

\section{OIAPOQUE E OS SEUS ESPAÇOS TURÍSTICOS}

A extensão da costa do estado do Amapá é de 698km segundo dados do Instituto Brasileiro de Geografia e Estatísticas - IBGE (BRASIL, 2010). Além disso, o estado apresenta grande biodiversidade, por estar localizado na Amazônia Brasileira. Durante o período colonial, o município de Oiapoque era parte da Capitania do Cabo Norte. No início do século XVI, os portugueses da América travam lutas com outros europeus para estabelecer domínio territorial ao sul do rio Oiapoque, na época conhecido como Vicente Pinzón e ao norte do rio Amazonas, para expandir os impérios colonizadores que cada grupo representava. Os primeiros habitantes da região são antepassados dos povos Waiãpi, que ocupavam a extensão territorial do rio Oiapoque, dos Galibi e Palikur, concentrados no vale do rio Uaçá e seus afluentes. (IBGE, 2014). 
Segundo o Instituto Brasileiro de Geografia e Estatísticas (BRASIL, 2010), o município de Oiapoque está distante cerca de $591 \mathrm{~km}$ da capital, Macapá e ocupa uma área de $22.625 \mathrm{~km}^{2}$. Com população estimada em 2010 de 25.514 habitantes, é o quarto município em número de habitantes do estado e sua densidade demográfica, em 2010, era de 0,91 por $\mathrm{km}^{2}$. Apesar do aumento no Índice de Desenvolvimento Humano experimentado nas últimas décadas, passando de 0,388 no ano de 1991 para 0,658 no ano de 2010, Oiapoque é o nono colocado no ranking dos dezesseis municípios que compõem o estado do Amapá.

Localizado na fronteira franco-brasileira, o município de Oiapoque se insere no Extremo Norte do Amapá (Figura 01), o qual, por sua vez, faz parte da Amazônia Brasileira, que segundo Freitas (2013) apresenta enorme riqueza em biodiversidade e potencialidades naturais, mas que, ao mesmo tempo, [...] "sua ocupação e povoamento é resultado de um longo processo, marcado por enormes conflitos entre os antigos habitantes e os povos colonizadores, predominantemente, os portugueses, que ainda no século XVI tiveram acesso ao grande potencial dos recursos naturais".

Figura 01. Situação de Oiapoque no estado do Amapá.

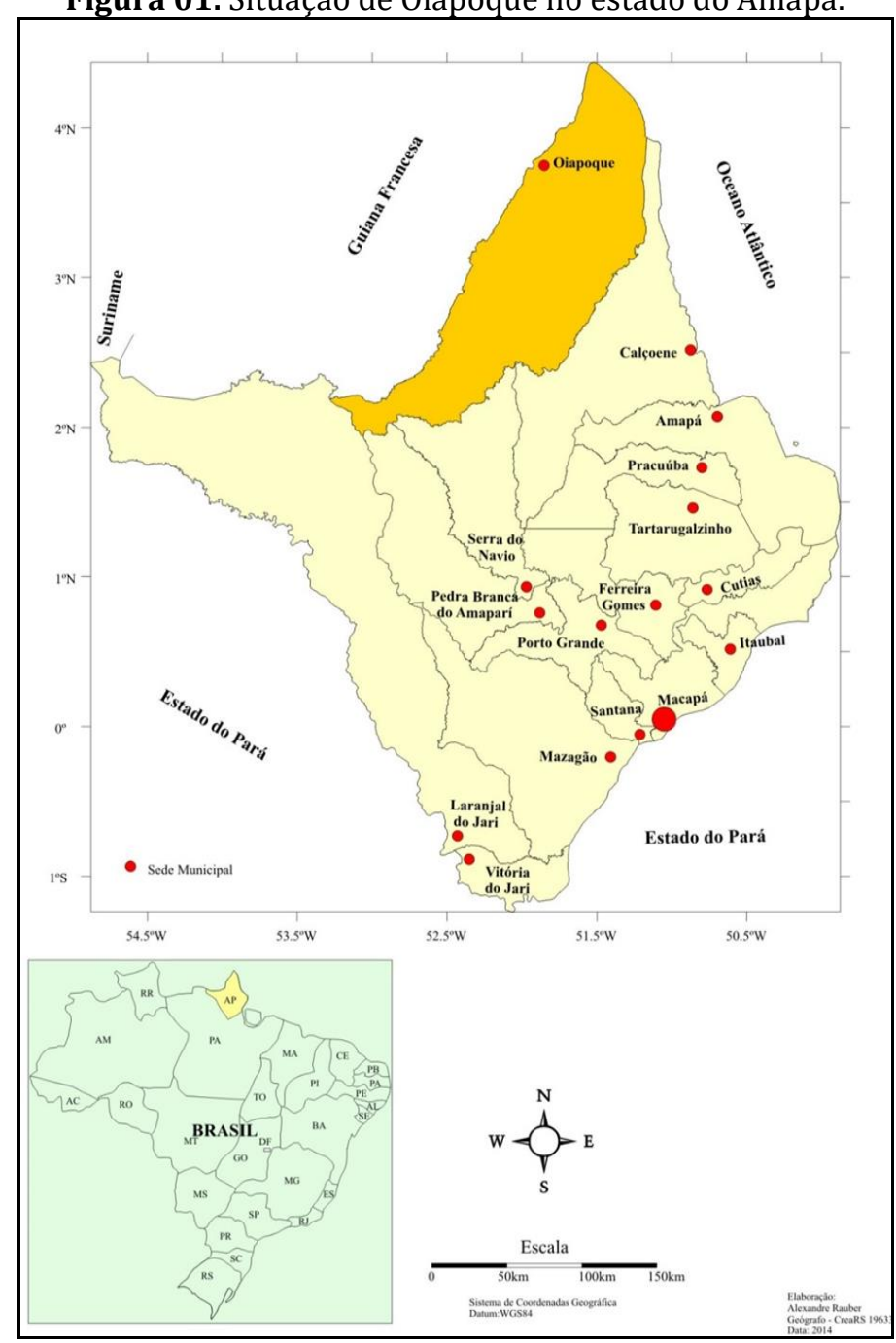

Fonte: Elaborado por Alexandre Rauber (2014) 
A configuração físico-natural da bacia do rio Oiapoque é fundamental para a biodiversidade rica e complexa ali presente. Dados do Instituto Brasileiro do Meio Ambiente e dos Recursos Naturais Renováveis (IBAMA) apontam que em 2007 a Amazônica Legal contava com 21 parques nacionais. Duas grandes áreas de proteção ambiental compõem a paisagem "natural" do Oiapoque: 0 Parque Nacional do Cabo Orange (PNCO) e o Parque Nacional Montanhas do Tumucumaque (PNMT). 0 Instituto Chico Mendes de Conservação da Biodiversidade (ICMBio), juntamente com a Ceres Inteligência Financeira, realizaram em 2011 o "Estudo de Viabilidade Econômica para a visitação embarcada no Parque Nacional do Cabo Orange". Como objetivo do estudo consta o de analisar a viabilidade econômica no sentido implementar o programa turístico de visitação embarcada ao PNCO.

Os rios da região como importantes vias para a movimentação e transporte de mercadorias e pessoas apresentam sérias limitações ao tráfego de embarcações. Alguns trechos apresentam sequência de corredeiras encachoeiradas que se fazem presentes a partir do seu curso médio (OAIPOQUE, 2015). Nesse contexto, o rio Oiapoque nas proximidades da cidade de Oiapoque serve, também, ao turismo uma vez que é utilizado para transporte de pessoas entre São Jorge de Oiapoque, na Guiana Francesa e Oiapoque no Brasil. As Figuras 02 e 03 mostram o conjunto da floresta, rio e transporte fluvial por catraias.

Figura 02. Paisagem do Rio Oiapoque.

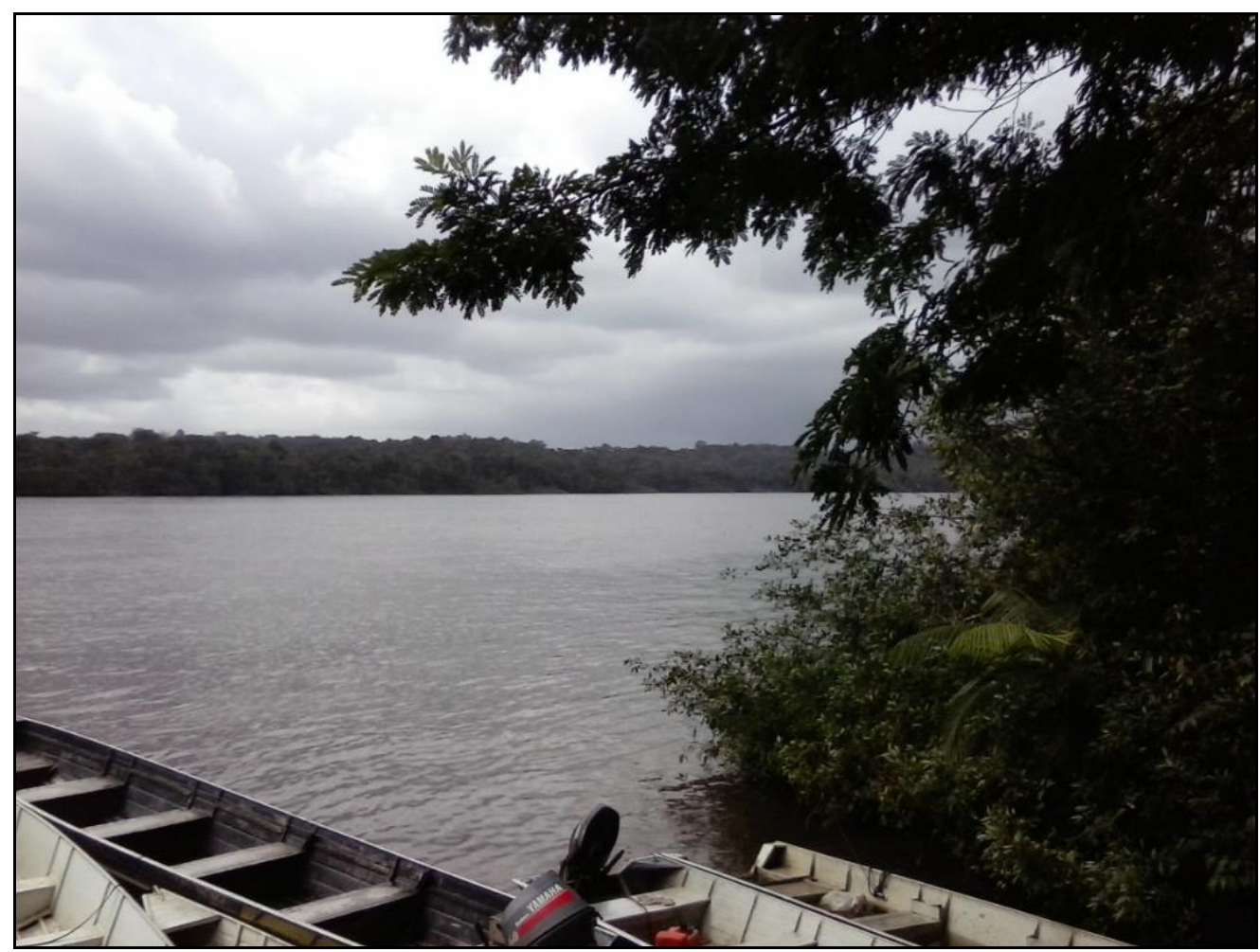

Fonte: trabalho de campo. 
Figura 03. Embarcações no Rio Oiapoque.

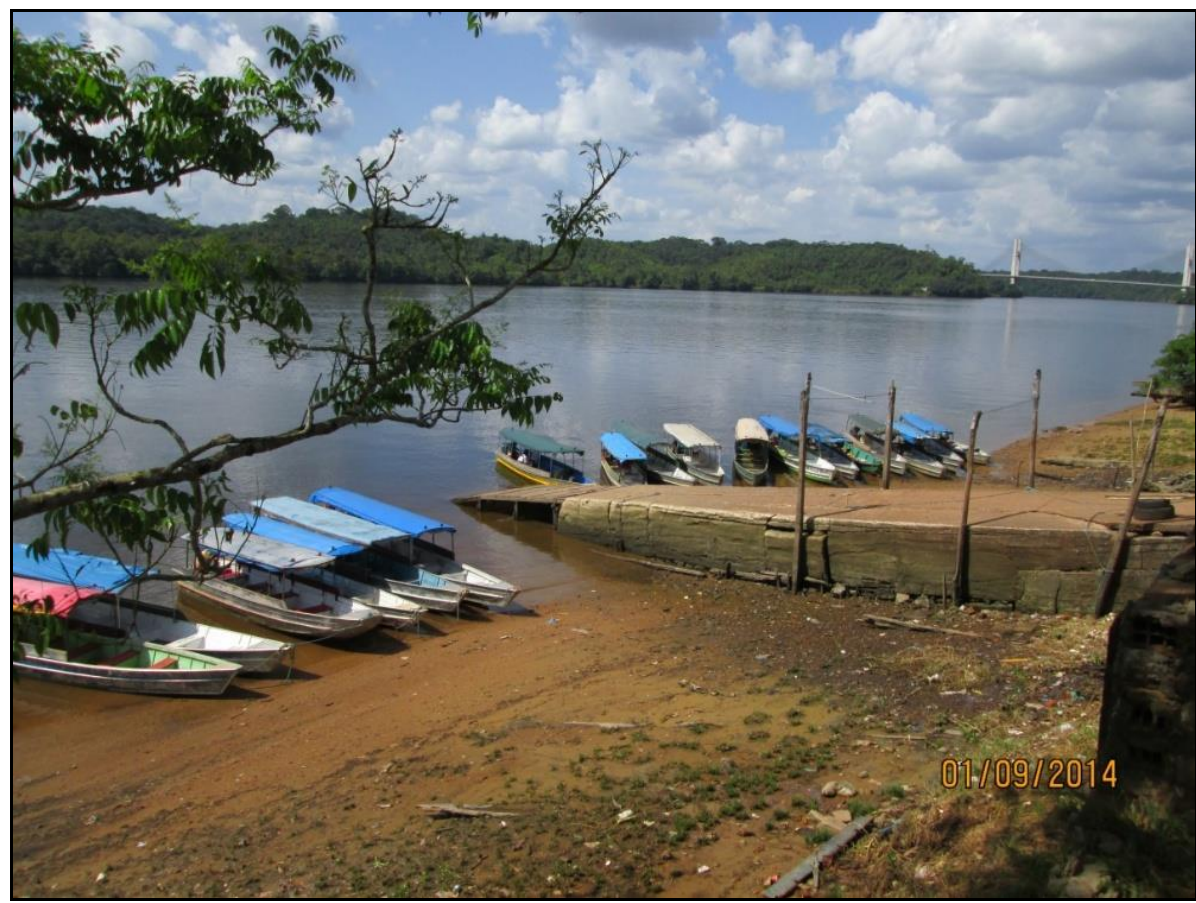

Fonte: trabalho de campo.

A fisiografia desse município destaca a contribuição parcial das bacias hidrográficas dos rios Oiapoque, Cassiporé e Uaçá e a presença de dois domínios naturais: o domínio da floresta densa de terra firme e o domínio das áreas inundáveis.

Levando-se em consideração a paisagem natural do município, percebe-se que a diversidade da paisagem é ferramenta fundamental para a realização do turismo. Nesse sentido faz-se mister lembrar que a percepção da paisagem perpassa por todos os sentidos do homem, uma vez que ela se constitui de aspectos estéticos, culturais e ecológico-geográficos. A diferença entre potencial e atrativo turístico reside no fato de equilíbrio e recursos, daí a importância da paisagem na realização do turismo.

Segundo a prefeitura Municipal de Oiapoque (OIAPOQUE, 2015), o perímetro urbano comporta 10 bairros sendo eles: Centro, Universidade, Florestal, FM, Infraero/Quilombola, Nova Esperança, Nova União, Paraíso, Planalto e Russo. Com crescimento da população que vem ocorrendo nos últimos anos, a cidade passou por um processo de urbanização sem planejamento, fato comum a grande parte dos municípios brasileiros.

Sobre o potencial turístico da fronteira em tela, Silva (2014) destaca que os fatores naturais tais como os rios Cassiporé, Cunani, Oiapoque, Grande Crique e Uaçã, constituem-se importantes potencialidades. Este mesmo autor ainda acrescenta a esse bojo de potencialidades turísticas em Oiapoque, os fatores culturais como o carnaval, a cultura indígena, o artesanato, os monumentos/marcos históricos e o Museu Kuahí. 
Por se tratar de uma região fronteiriça - a fronteira franco-brasileira -, Oiapoque, no Brasil, e Saint Georges de L'Oyapok, na Guiana Francesa são consideradas pelo Ministério da Integração Nacional (BRASIL, 2005), como cidades gêmeas. Isso significa dizer que, se por um lado, a própria situação geográfica, ou seja, a localização dessas duas cidades estimula a interação das populações ali existentes, por outro lado, quando se considera que se tratam de dois países distintos, não se pode deixar de ponderar que os interesses e as formas como as políticas territoriais sobre esses territórios apresentam diferenças substanciais. Considere-se o que diz Silva (2014, p. 103):

\begin{abstract}
Essas áreas podem desenvolver outros interesses que não são os do Governo Central, à medida que elas podem passar a representar, também, uma ameaça à ordem constituída, tornando-se uma preocupação constante dos estados em termos de sua garantia, controle e fiscalização. Elas (as cidades gêmeas e Oiapoque e Saint Georges de L'Oyapoque) têm um papel expressivo na dinâmica dos países e representam desafios concretos na consolidação da soberania dos Estados.
\end{abstract}

Dados de campo, bem como notícias e debates veiculados em redes sociais na internet reforçam que a ideia de que os diferentes interesses por parte dos poderes públicos dos dois países interferem fortemente no processo de realização desses dois espaços. Isso, claro, é reforçado, quando se atenta para o fato de que as diferenças dos índices relacionados ao desenvolvimento humano, ao desenvolvimento urbano, aos investimentos públicos nas áreas de infraestrutura, segurança, e políticas sociais de forma geral, são objetos de frequentes comparações entre os dois lados da fronteira. Sinais dessas assimetrias da organização espacial da fronteira franco-brasileira podem ser observadas na paisagem urbana da fronteira (Figuras 04 e 05).

Figura 04. Oiapoque - Rua Santos Dumont.

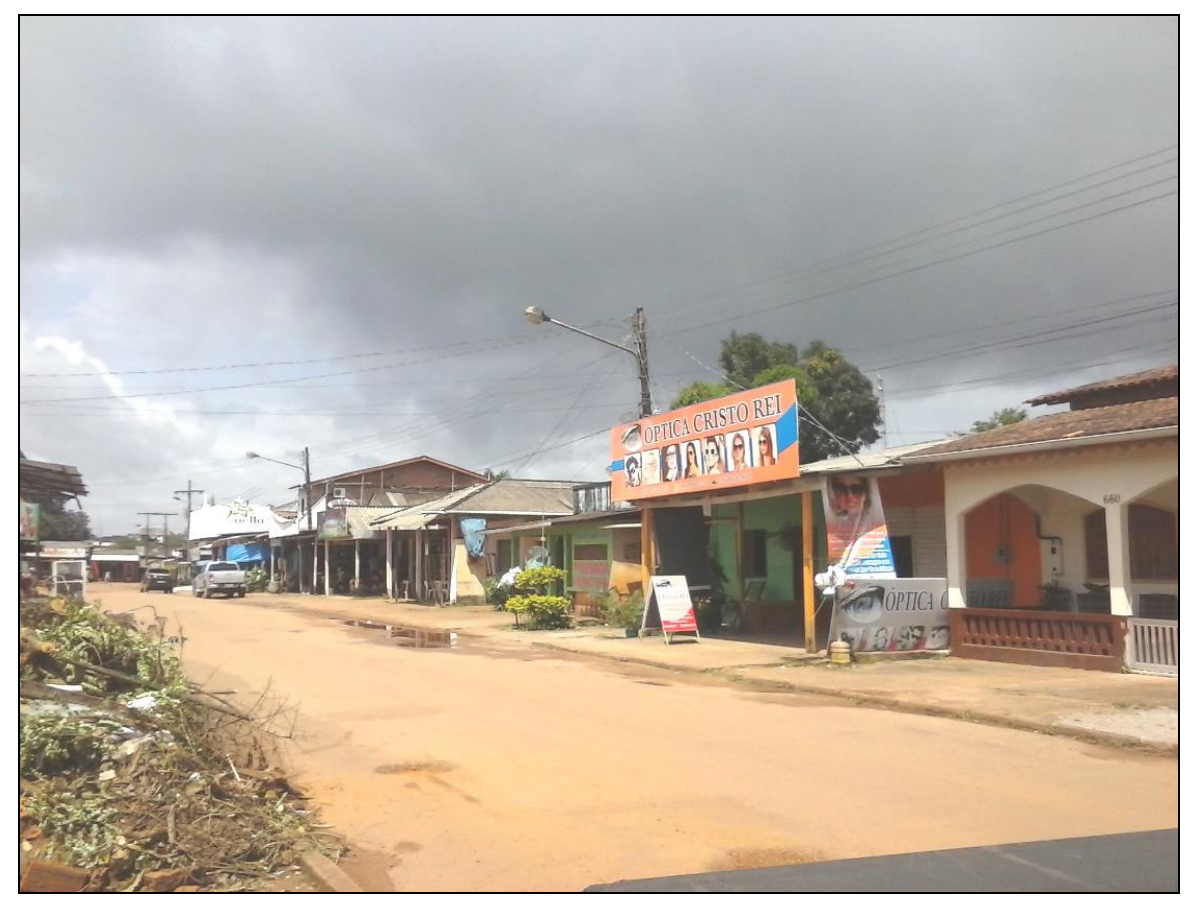

Fonte: trabalho e campo, 2015. 
Figura 05. Saint Georges de L’Oyapock - Rue Henry Sebeloue.

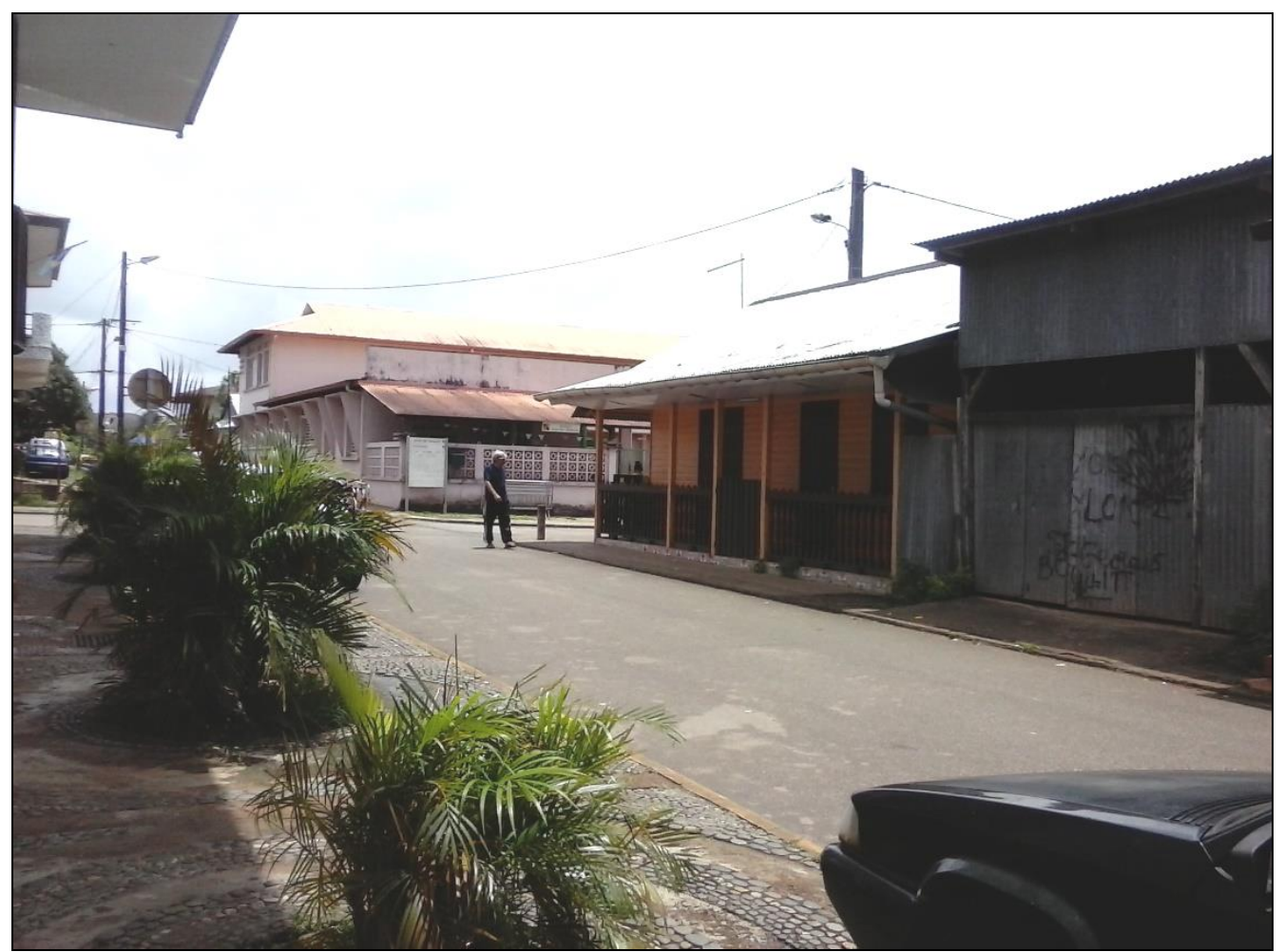

Fonte: trabalho de campo, 2015

É diante desse contexto de disparidades que a Ponte Binacional sobre Rio Oiapoque, a qual foi pensada a partir de esforços e acordos bilaterais entre os dois países, ainda no século passado, encontra-se finalizada sua estrutura física, sem, contudo, ter sido inaugurada. Isso permite dizer que as articulações no âmbito das políticas internacionais entre Brasil e França necessitam caminhar na direção da eliminação de entraves significativos.

Se por um lado, a paisagem urbana de Oiapoque não demonstra uma configuração urbanística atraente, por outro, constitui-se de potencial para o turismo na fronteira, considerando-se que parte dos turistas originários da Guiana Francesa ou da França Metropolitana, compreendem tal configuração como "pitoresca". Ao mesmo tempo, turistas brasileiros visitantes na Guiana Francesa experimentam a mistura da vida cultural complexa desta, marcada por décadas de imigração de vários povos chineses, europeus, haitianos, dominicanos e de algumas nações sul-americanas como do próprio Brasil.

De maneira geral, o desenvolvimento do turismo na Guiana Francesa e no Amapá é freado, também, pela falta de infraestrutura para a recepção de qualidade (agências de viagem, hospedagem, etc.) e de profissionais com qualificação formal para esta atividade (poucos cursos de turismo e dificuldade no domínio de línguas estrangeiras). Na Guiana Francesa, os equipamentos hoteleiros não apresentam mudanças substanciais desde 1993, ou seja, há mais de 10 anos. 
As políticas diretamente ligadas ao turismo na fronteira, em sua maioria acontecem com alguma integração entre os dois países (Brasil e França). Algumas destas políticas não são efetivadas, geralmente por não serem mantidos os acordos bilaterais. Destacam-se projetos como: Programa de Gestão Integrada da Fronteira da Zona Estuarina do Rio Oiapoque; Projeto de Experimentação do Turismo de Base Comunitária no Parque Nacional do Cabo Orange, dentro de uma Rota Integrada Guiana Francesa-Brasil; Programa de Monitoramento Integrado da Área Estuarino-Marinha da Fronteira Brasil e Guiana Francesa (ICMBIO; CERES, 2011), dentre outros.

Esses projetos apresentam potencialidades turísticas expressivas, especialmente o ecoturismo. Contudo, não se pode deixar de considerar que essas as políticas acontecem de forma desarticulada entre os agentes públicos dos dois países e dos agentes privados. Vale ressaltar, ainda, que as políticas públicas contribuem para que haja infraestrutura necessária à realização do turismo. Fato que não ocorre na fronteira franco-brasileira. Se do lado de Saint Georges, a ligação com a capital do Departamento Ultramarino (Caiena) ocorre pela rodovia RN2, pavimenta e sinalizada, a ligação entre Oiapoque e a capital do estado do Amapá, Macapá ocorre pela rodovia BR-156, com mais de $100 \mathrm{~km}$ sem asfaltamento e, ao mesmo tempo dependente das condições climáticas da região. A Figura 06 mostra veículos e pessoas na rodovia BR-156 impossibilitadas de seguir viagem devido às péssimas condições em período de chuvas.

Figura 06. Trecho da rodovia BR -156

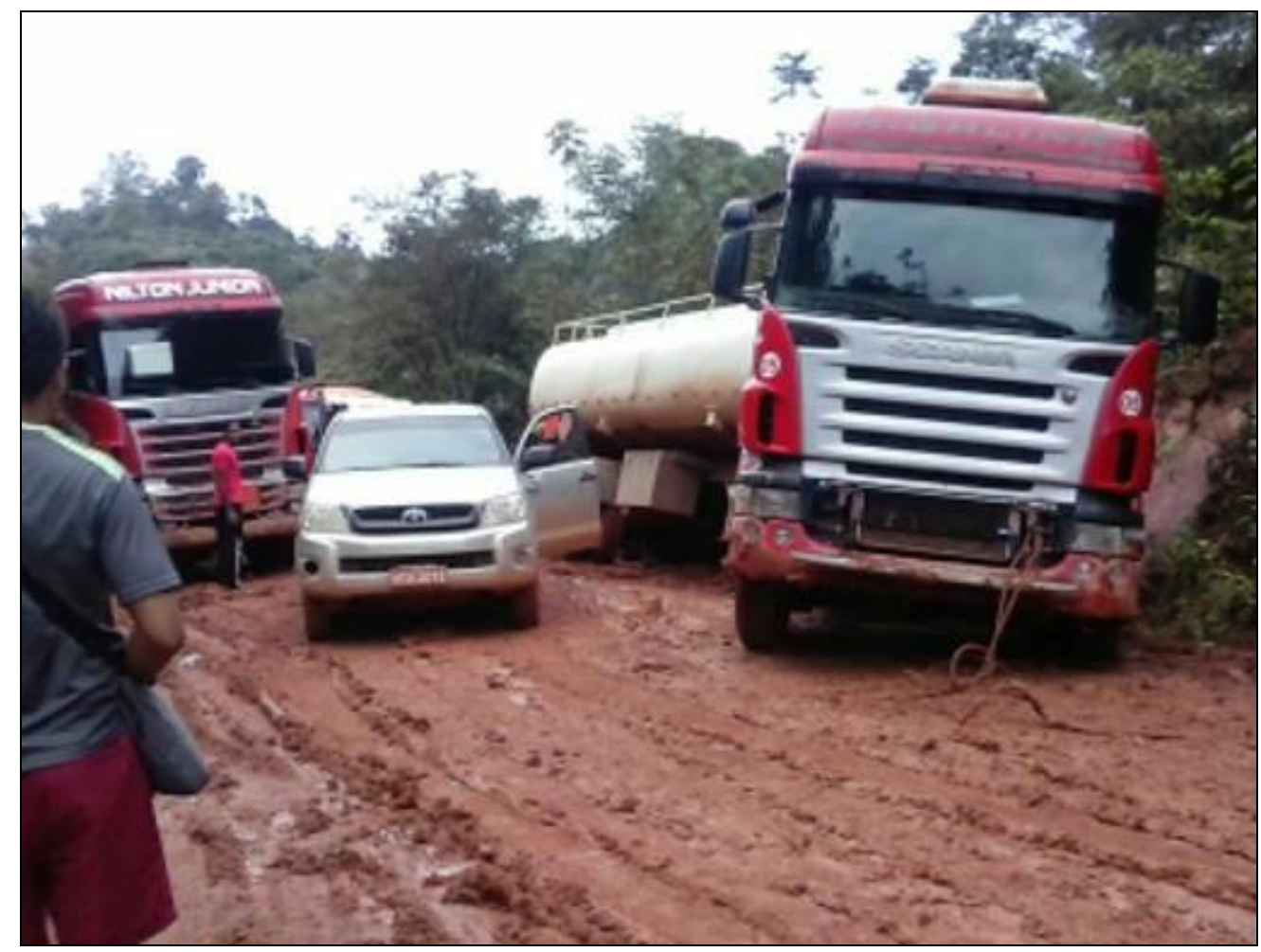

Fonte: acervo pessoal, julho de 2014. 
As dificuldades no trajeto entre Oiapoque e Macapá repercutem diretamente na qualidade de vida dos residentes desta cidade. Dados de campo dão conta de que durante o período chuvoso, que dura mais de 06 meses (de janeiro a julho), os moradores de Oiapoque tornam-se "isolados" de Macapá. Sendo assim, não é de se impressionar que o Índice de Desenvolvimento Humano (IDH) deste município seja um dos mais baixos do país (0,658 segundo IBGE, 2010).

Esse "isolamento" periódico, por um lado desestimula o investimento privado no município, e por outro contribui para que as pessoas residentes em Oiapoque apresentem insatisfações quanto ao espaço vivido. Isso significa dizer que as políticas públicas na fronteira ainda não foram capazes de, sequer, permitir ao citadino o direito à cidade, que é condição sine qua non para a justiça social e à qualidade de vida.

Especificamente no que tange à infraestrutura, que deveria estar à disposição da população de Oiapoque, o que, por sua vez, contribuiria para o desenvolvimento do turismo, o Plano Municipal de Saneamento Básico de Oiapoque, afirma que a
A ineficiência em termos de infraestrutura acaba afetando o desenvolvimento do turismo local e se constitui como uma das principais reclamações não só de turistas e visitantes, mas também da população local. O reconhecimento do espaço como turístico depende também de melhorias na infraestrutura e da oferta de serviços e conforto aos turistas. (OIAPOQUE, 2015, p. 101).

Diante disso, como pensar em desenvolvimento do turismo local se à população residente nesse espaço, sequer é possibilitada qualidade de vida? E os tantos outros aspectos importantes para o desenvolvimento socioespacial? Claro que a configuração de baixo desenvolvimento humano, desigualdades sociais, etc. pode ser observada em todo o Brasil. Contudo, no caso em tela, a questão é potencializada quando as políticas públicas neste não dão conta ainda de resolver problemas básicos de infraestrutura urbana.

No que tange a importância de se considerar todas as dimensões para assim promover desenvolvimento do turismo, Beni (2004) é enfático em dizer que o turismo só é possível quando o sistema (SISTUR) é harmônico. Em outras palavras, pensar em turismo sem considerar a articulação efetiva entre o Conjunto da Organização Estrutural, com os conjuntos das Relações ambientais e das Ações Operacionais leva, inevitavelmente, ao fracasso. Ao mesmo tempo, Yázigi (2001, p. 291) diz que "Sem a superação do abismo social e da arbitrariedade na esfera pública, não pode existir um teor comunitário propício ao turismo". Ou seja, o apoio técnico e político ao turismo deve ser permeado de apoio técnico e político às políticas públicas de forma geral. Do contrário, continua-se desperdiçando recursos financeiros e humanos, sem promover desenvolvimento humano, e claro, turístico. 


\section{CONSIDERAÇõES FINAIS: A SIGNIFICAÇÃo E A REPERCUSSÃo DAS POLÍTICAS PÚBLICAS DE TURISMO EM OIAPOQUE}

Embora haja articulação com as ações dos governos no sentido de alavancar o turismo no município, Oiapoque precisa criar mecanismos que o torne efetivamente atrativo. Cabe à gestão pública municipal, desenvolver ações que atraiam investimentos reais das demais escalas de governo. É preciso que haja investimentos públicos no sentido de criar infraestruturas turística etc. 0 turismo deve ser incluído efetivamente nas políticas públicas desenvolvidas para o município. Até o momento, o único instrumento da gestão municipal, no que tange ao turismo, é a Secretaria de Turismo e Cultura, a qual, por sua vez, busca implementar diretrizes do Conselho de Turismo e o Plano Municipal de Turismo como ferramenta institucionalizada para planejar o turismo local. Contudo, os depoimentos dos gestores municipais do turismo dão conta de que Oiapoque não está inserida no contexto do turismo no estado, no país e muito menos no turismo internacional.

Ao que parece, faz-se necessária a elaboração de políticas municipais de turismo, uma vez que se constitui de instrumento fundamental para o desenvolvimento do município, dando ênfase na inserção dos próprios moradores na atividade. Também é necessário definir formas de fiscalização, adotar parâmetros de controle dos serviços executados, fixar direitos e deveres dos usuários, estabelecer mecanismos de controle social dentre outros.

Até o momento, percebe-se que em Oiapoque o papel dos agentes sociais não é considerado no processo de produção dos espaços turísticos, repercutindo na reprodução de um espaço socialmente injusto, com pouca ou nenhuma perspectiva de mudanças positivas para a população local.

0 turismo está condicionado a diferentes políticas públicas de caráter territorial como: transportes, construção civil, comércio e nos diversos setores que fornecem produtos ou serviços relacionados a viagens de lazer e de negócios. Persistem questões que perpassam pela busca do entendimento/análise das políticas públicas implementadas para o fortalecimento do turismo. Isso, sem perder de vista que a atividade do turismo, assim como nenhuma atividade econômica, é capaz sozinha de promover o desenvolvimento socioespacial

Para que o turismo em Oiapoque e no Amapá seja desenvolvido, faz-se necessário que sejam utilizados mecanismos dinamizadores do potencial já existente. Isso, claro, considerando-se no planejamento e na gestão desse turismo a dimensão local, ou seja, a dinâmica espacial da região. Pensar em desenvolvimento do turismo que não leve em conta a realidade socioespacial local, ou seja, a configuração territorial significa repetir erros, desperdiçar recursos e perder oportunidade de promover justiça social e melhora da qualidade de vida.

Isto posto, vale destacar que a significação e a repercussão das políticas públicas de turismo em Oiapoque, não se encerram com o presente texto. Pelo contrário, o debate acerca do desenvolvimento 
do turismo e dos espaços turísticos naquele município aponta a necessidade da realização de estudos mais aprofundados. Compreender a realidade do turismo e das políticas públicas, considerando que grande parte delas tem base territorial, é uma das questões que se coloca. Em outras palavras, se as políticas de modernização no Brasil pautaram-se na modernização do território, com criação de infraestruturas, por exemplo, outros estudos podem contribuir para o debate, ao analisar as infraestruturas que foram criadas pelo Estado, no Amapá e em Oiapoque, que em alguma medida colaboram para o turismo. Outra questão que se coloca, diz respeito ao fato de que sendo o Estado o grande agente modernizador do território, reflexões sobre o tema do turismo e dos espaços turísticos, à luz do debate sobre políticas territoriais parecem pertinentes.

Diversos são os temas relacionados ao turismo e aos espaços turísticos que se destacam como relevantes para investigações geográficas que, ao mesmo tempo, não negligenciem o caráter plural dessa área do conhecimento e as suas conexões com outras. Ao trazer algumas notas acerca das políticas públicas e dos espaços turísticos em Oiapoque, espera-se contribuir para o debate que não perca de vista o fenômeno turístico, o lugar, a paisagem, o território a sua dimensão socioespacial, portanto, não apenas econômico.

\section{REFERÊNCIAS}

ANDRADE, José Vicente de. Turismo: fundamentos e dimensão. 5 Ed. São Paulo: Ática, 1998.

BARRETTO, Margarita. Manual de iniciação ao estudo do turismo. Campinas: Papirus, 1995. . Planejamento responsável do turismo.

Campinas: Papirus, 2005.

BENI, Mário Carlos. Análise estrutural do turismo. 2.ed. São Paulo: SENAC, 1998.

. Globalização do turismo: megatendências do setor e a realidade brasileira. 2 ed. São Paulo: Aleph, 2004.

BRASIL/IBGE. Instituto Brasileiro de Geografia e Estatística. Cidades. 2010. Disponível em: <http://www.ibge.gov.br>. Acesso em: 23 set. 2014

. Censo Demográfico 2010.

CASTILHO, Cláudio Jorge Moura de. VIEGAS, Jeanete Magalhães. Turismo e práticas socioespaciais: múltiplas abordagens e interdisciplinaridades. Recife: Ed. UFPE, 2006.

; SELVA, Vanice Santiago Fragoso (Org.).

Turismo, políticas públicas e gestão dos ambientes construídos. Recife: Ed. UFPE, 2012.

CASTRO, Iná Elias de; GOMES, Paulo Cesar da Costa; CORRÊA, Roberto Lobato (orgs.). Olhares geográficos: modos de ver e viver o espaço. Rio de Janeiro: Bertrand Brasil, 2012.
CORIOLANO, Luzia Neide M. Teixeira. Do local ao global: o turismo litorâneo cearense. Campinas: Papirus, 1998.

FLICK, Uwe. Introdução à pesquisa qualitativa. Tradução Joice Elias Costa. 3a ed. Porto Alegre: Artmed, 2009.

HÖFLING, Eloisa de Mattos. Estado e políticas (públicas) sociais. Cadernos Cedes, ano XXI, no 55, novembro/2001. P. 30 - 41.

INSTITUTO CHICO MENDES DE CONSERVAÇÃO DA BIODIVERSIDADE (ICMBIO); CERES INTELIGÊNCIA FINANCEIRA. Estudo de Viabilidade Econômica para a visitação embarcada no Parque Nacional do Cabo Orange. Belo Horizonte, Os autores... mimeo, 2011.

OIAPOQUE/Prefeitura Municipal de Oiapoque Plano Municipal de Saneamento Básico (PMSB), 2015.

PHILIPP JR, Arlindo, PELICIONI, Maria Cecelia Foceli. Educação ambiental e sustentabilidade no turismo. Barueri: Manole, 2009.

RIO, Gisela A. Pires. A espacialidade da economia: superfícies, fluxos e redes. In: CASTRO, Iná Elias de; GOMES, Paulo Cesar da Costa; CORRÊA, Roberto Lobato (orgs.). Olhares geográficos: modos de ver e viver o espaço. Rio de Janeiro: Bertrand Brasil, 2012.

RUBINO, M. Silvia. Políticas públicas de turismo: a hospitalidade pública ao excursionista em 
Bertioga. 2004. 168 f. Dissertação (Mestrado em Hospitalidade), Universidade Anhembi Morumbi, São Paulo, 2004.

SANTOS, Milton. Economia espacial: críticas e alternativas. Áão Paulo: EDUSP, 2011.

SECCHI, Leonardo. Políticas públicas: conceitos, esquemas de análise, casos práticos. São Paulo: Cengage Learning, 2010.
SILVA, G.V.. Oiapoque: Potencialidades e caminhos neste século XXI. Macapá: EDUNIFAP, 2014.

YÁZIGI, Eduardo. Turismo: uma esperança condicional. 2.ed. rev. e ampl. São Paulo: Global, 1999.

. A alma do Lugar: turismo, planejamento e cotidiano em litorais e montanhas. $2^{\mathrm{a}}$ ed. São Paulo: Contexto, 2001. 